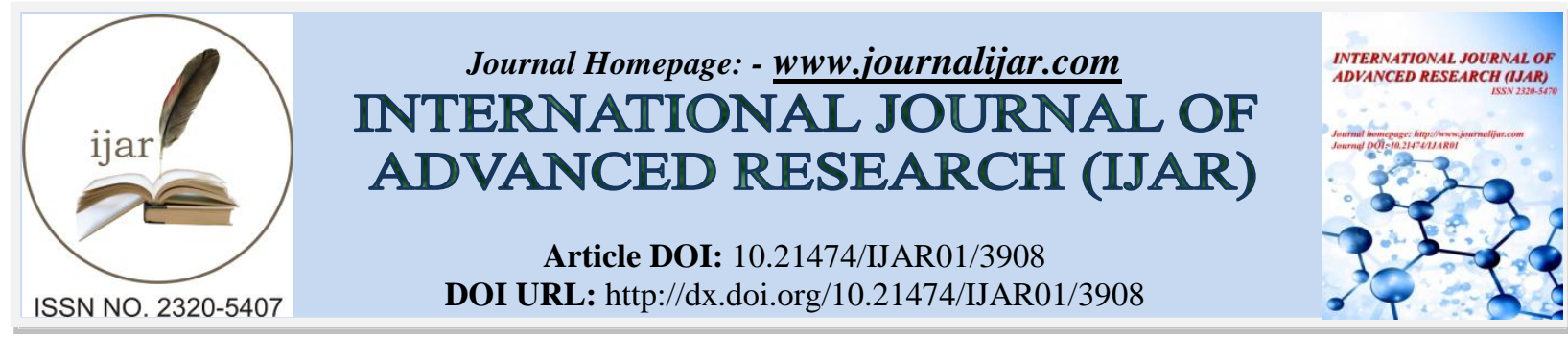

RESEARCH ARTICLE

\title{
IMUNNOLOGICAL AND STRUCTURAL ANALYSIS OF HPV-POSITIVE CERVICAL CARCINOMA CELL LINES AND BOVINE PAPILLOMAVIRUS VIRUS-LIKE PARTICLES (BPV-VLP).
}

Dra. Rachel Siqueira de Queiroz Simões and Dra. Ortrud Monika Barth.

Laboratory of Morphology and Viral Morphogenesis, Instituto Oswaldo Cruz, Fundação Oswaldo Cruz, Avenida Brasil 4365, Manguinhos, 21040-900, Rio de Janeiro, RJ, Brazil. E-mail: rachel.simoes@ioc.fiocruz.br

\section{Manuscript Info}

Manuscript History

Received: 16 February 2017

Final Accepted: 19 March 2017

Published: April 2017

Key words:-

cell lines, HPV-positive, morphology, papillomavirus, ultrastructure.

\begin{abstract}
This paper reported about morphological alterations occurring inside HPV-positive cervical carcinoma cell lines and BPV infection. The wart samples were collected from animals affected by cutaneous papillomatosis and previously detected using PCR. The ultrastructural cell morphology in SiHa (HPV-16) and HeLa (HPV-18) cell lines $\left(3 \times 10^{6}\right.$ cells) detected by electron microscopy were also investigated. Few studies have assessed the transmission electron microscopy in different cell lines. Morphologically, very electron-dense cells were detected presenting well developed mitochondria and rough endoplasmic reticulum (rER), many vesicles and ribosomes in HeLa and $\mathrm{SiHa}$ cell lines. Cellular modifications similar to antigen-presenting cells, many activated mitochondria and vesicle transport were well preserved. Furthermore, the presence of VLP and cellular junctions like desmosomes were also detected in BPV samples. These morphological alterations suggest a high cellular activity of HPV-positive ( $\mathrm{SiHa}$ and HeLa) cell lines and can be possible prognostic markers of cervical cancer. These results point to the potential to induce tumors that probably involves mechanisms of oncoproteins to produce virions and differentiation of keratinocytes in the epithelial layers remains to be elucidated.
\end{abstract}

Copy Right, IJAR, 2017. All rights reserved.

\section{Introduction}

Papillomaviruses (PVs) have closed circular double-stranded DNA genome (8kb) presenting icosahedral capsid structural proteins, composed of the L1 (major) and L2 (minor), which can spontaneously co-assemble to form virus like particles. Cell transfection method for efficient intracellular assembly of papilloma viral vectors have been developed using bovine papillomavirus type 1 (BPV1) and human papillomavirus type 16 (HPV 16) as model papillomaviruses (Buck et al., 2004). Previous studies have been described an infectious HPV pseudovirion (PsV), comprising an HPV capsid containing a reporter plasmid as a surrogate virus (Buck et al., 2004).

New therapeutic targets to HPV vaccination have been described including DNA-based vaccines, recombinant proteins, nanoparticles, synthetic peptides, viral and non-viral vectors (Simões \& Barth, 2015) and expressed chimeric proteins self-assembled into virus like particles (VLP) from L1 major capsid proteins to produce HPV vaccines (Huber et al., 2017).

Corresponding Author: Dra. Rachel Siqueira de Queiroz Simões.

Address: Laboratory of Morphology and Viral Morphogenesis, Instituto Oswaldo Cruz, Fundação Oswaldo Cruz, Avenida Brasil 4365, Manguinhos, 21040-900, Rio de Janeiro, RJ, Brazil. 
L1 protein self-assembled into VLP presented inside HPV vaccine is immunologically and morphologically similar to native virions. L2 structural proteins minor capsid also induced high-titer neutralizing antibodies as the main mechanism of vaccine efficacy. Both proteins are used as synthetic peptides in studies about immune responses in BPV-1 and HPV-16 (Huber et al., 2017).

There are several phenotypes of antigen-presenting cells (Langerhans cell, Migratory LC, Langerin dendritic-cell populations, dermal macrophages) in the skin which are migratory in the epithelial tissue. Merad et al. (2008) described different cellular markers in the skin and skin-draining lymph nodes in mice and humans.

The expression of genes and the role of proteins involved in DNA damage repair pathways in cell lines as primary human keratinocytes (PHK) and HPV-positive (SiHa - HPV-16 and HeLa - HPV-18) and HPV-negative (C33A) human cervical carcinoma cell lines, as also in immortalized keratinocyte cell lines (HaCaT, not tumor control) have been described as possible prognostic markers of cervical cancer. Some studies have investigated the ability of the cytokine to inhibit the proliferation "in vitro" of normal and HPV infected keratinocytes, as well as the expression of E6 and E7 oncogenes (Prati, 2014).

Cytokines include the growth factor (TGF- $\beta$ ), tumor necrosis factor (TNF) and interferons type I (IFN- $\alpha$ and IFN- $\beta$ ), which are produced by epithelial cells. The cytokine TGF- $\beta$ has proved to be an inducer and inhibitor growth of tumor cells not infected by HPV 16 and 18. This effect appears to be associated with inhibition of E6 and E7 expression (Braun et al, 1992). IFN- $\alpha$ inhibits transcription of E6 and E7 genes in HPV-18 HeLa cells and also inhibits the expression of the E7 protein of HPV-16 (Khan et al, 1993; Perea et al, 1995)

In contrast, few studies have investigated the cell pathomechanisms and morphological changes in the host cells. The present study report the presence of the bovine papillomavirus virus-like particles (BPV-VLP) and morphological alterations inside the host cells in previously PCR positive samples from bovines affected by cutaneous papillomatosis. Additionally, described the morphology of HPV-positive ( $\mathrm{SiHa}$ and HeLa) cervical carcinoma cell lines detected by electron microscopy.

\section{Material and Methods}

Warts samples and cell lines:

Warts lesions from bovines of a typical cauliflower-like appearance were collected by surgical procedures using disposable gloves and scalpels and immediately stored on dry ice and formalin according to each techniques used. HPV-positive human cervical carcinoma cell lines as SiHa (HPV-16) and HeLa (HPV-18) were cultivated in RPMI medium. About $3 \times 10^{6}$ cells were counted and selected to molecular and morphological studies.

\section{Histopathology Examination:}

For the histopathological observation, the tumor samples were fixed in $10 \%$ formalin, embedded in paraffin and stained with haematoxylin and eosin. The microscopical patterns observed were indicative of papillomavirus infection.

\section{Ultrastructure:}

For ultrastructural analysis, the specimens (warts and SiHa and HeLa cells) were embedded in epoxy resin, fixed in $1 \%$ glutaraldehyde and post-fixed in $1 \%$ osmium tetroxide. Later steps followed by washes in cacodylate buffer 0.2 $\mathrm{M}$ in sodium sucrose $0.7 \%$ and distilled water. The dehydration steps were performed and using $1 \%$ uranyl acetate in $70 \%$ acetone, followed by $90 \%$ and $100 \%$ acetone. Warts and lines cells were included in epoxy resin and kept at $60^{\circ} \mathrm{C}$ to complete polymerization. Ultra-thin sections, 50nm thick, were performed to electron microscopy observation. Semi-thin sections, $0.5 \mu \mathrm{m}$ thick, were performed to optical photonic microscopy observation. The ultra-thin sections were stained with uranyl acetate and lead citrate, the semi-thin sections with methylene blue (De Souza, 2001; Simões et al., 2014).

\section{Molecular:}

About 30mg of tissue were used for DNA extraction using the tissue kit (Qiagen) according to manufactures`s instructions. The primers amplified approximately $268 \mathrm{bp}$ fragment of the $\beta$-globin gene used to evaluate the quality of genomic DNA extracted from the samples: $\beta$-globin forward: 5 - AACCTCTTTGTTCACAACCAG-3') and $\beta$ globin reverse: 5'-CAGATGCTTAACCCACTGAGC-3`) (Yaguiu et al., 2006). DNA was used for polymerase chain reaction (PCR) analysis using degenerate primers. The PCR FAP59/FAP64 was originally designed to amplify 
a 478bp fragment of the L1 open reading frame in the conserved regions. The PCR primer pair FAP59/FAP64 was originally designed to amplify a 478bp fragment of the L1 open reading frame in the conserved regions. DNA samples were amplified using two PCR primer pairs: FAP 59 (forward: $5{ }^{`}$ - TAACWGTIGGICAYCCWTATT-3`) and FAP64 (Reverse: 5'-CCWATATCWVHCATITCICCATC-3`) (Forslund et al., 1999). PCR was executed in the same conditions applying the same primers used to verify the quality of DNA by $\beta$-globin gene. The samples were inserted in the thermocycler and followed the protocol described by Ogawa et al (2004). PV DNA-specific bands were identified by electrophoresis on a 1\% agarose gel in TBE buffer under UV light (Ogawa et al., 2004).PCR products were purified using GFX PCR DNA purification kit (GE Healthcare) and sequenced.

In order to optimize the current cell lines, DNA of SiHa and HeLa cells naturally infected with HPV-16 and -18, respectively, were extracted using DNA blood mini kit (Qiagen) and used as positives controls. The amplification mixture without DNA was used a negative control. MY09/11 consensus primers that amplify a 450 bp DNA sequence specific for HPV L1 ORF were used to positive standard samples.

\section{Results}

In the clinical evaluations papillomas were observed on the haired skin of the face, pinna and forelimbs. Histological examination of haematoxylin and eosin stained sections demonstrated epithelial hyperplasia, acanthosis, hyperkeratosis and tissue proliferation. The histopathological examination confirmed the characteristic of papillomavirus infection. Intranuclear corpuscular inclusions were observed by photonic microscopy. Strong electron-dense cells presenting well-developed mitochondria and numerous vesicles and rough endoplasmic reticulum (rER) were detected by electron microscopy (Figure 1).

By optical photonic microscopy we observed in both cell lines similar features such as presence of very large nuclei with highlighted nucleoli, reduced cytoplasm, cell membranes presenting filopodia, few vacuoles and interconnected cells by desmosomes. Very electrodense cells were detected by electron microscopy presenting well developed mitochondria and rough endoplasmic reticulum, many vesicles and ribosomes in HeLa and SiHa cell lines (Figure 2). Furthermore, HPV-DNA was amplified by PCR method using different amount of template (1-5 $\mu \mathrm{L})$ (Figure 3). These preliminary results suggested a strong cellular activation in these cervical keratinocytes. 

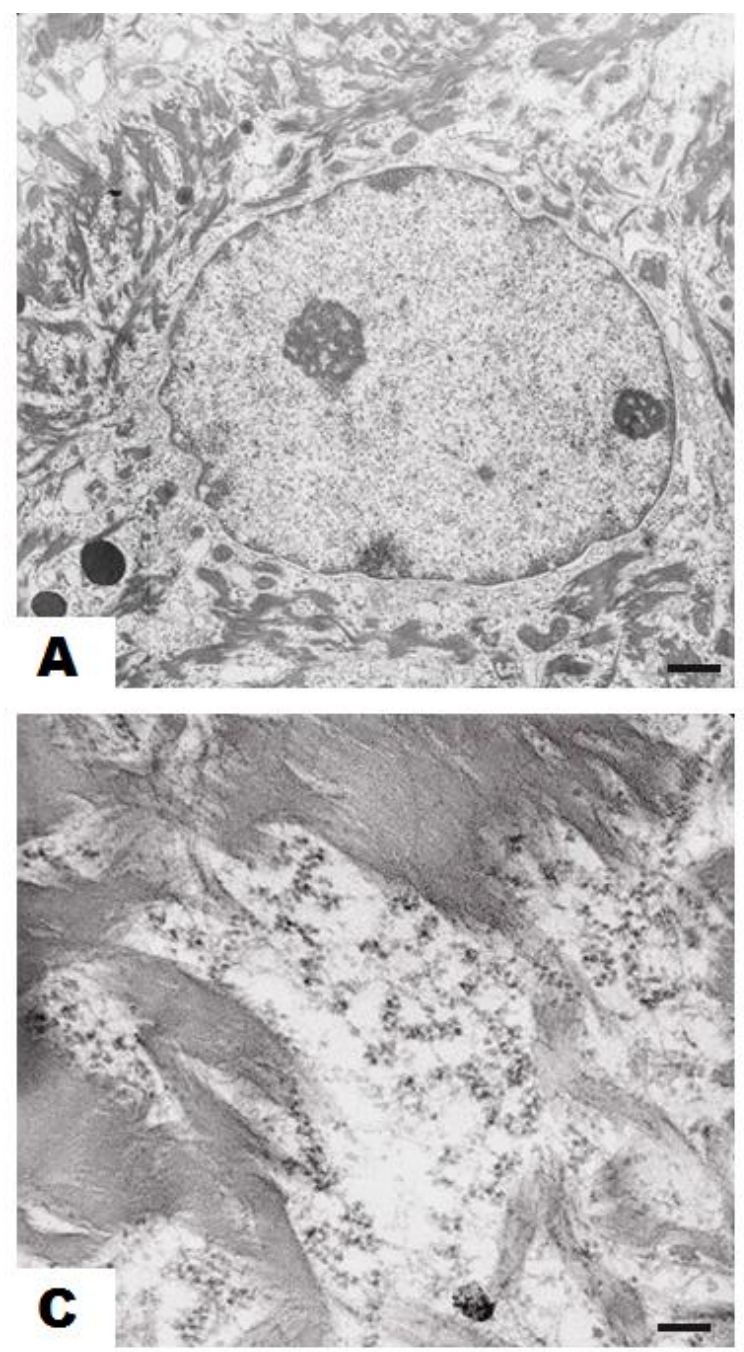
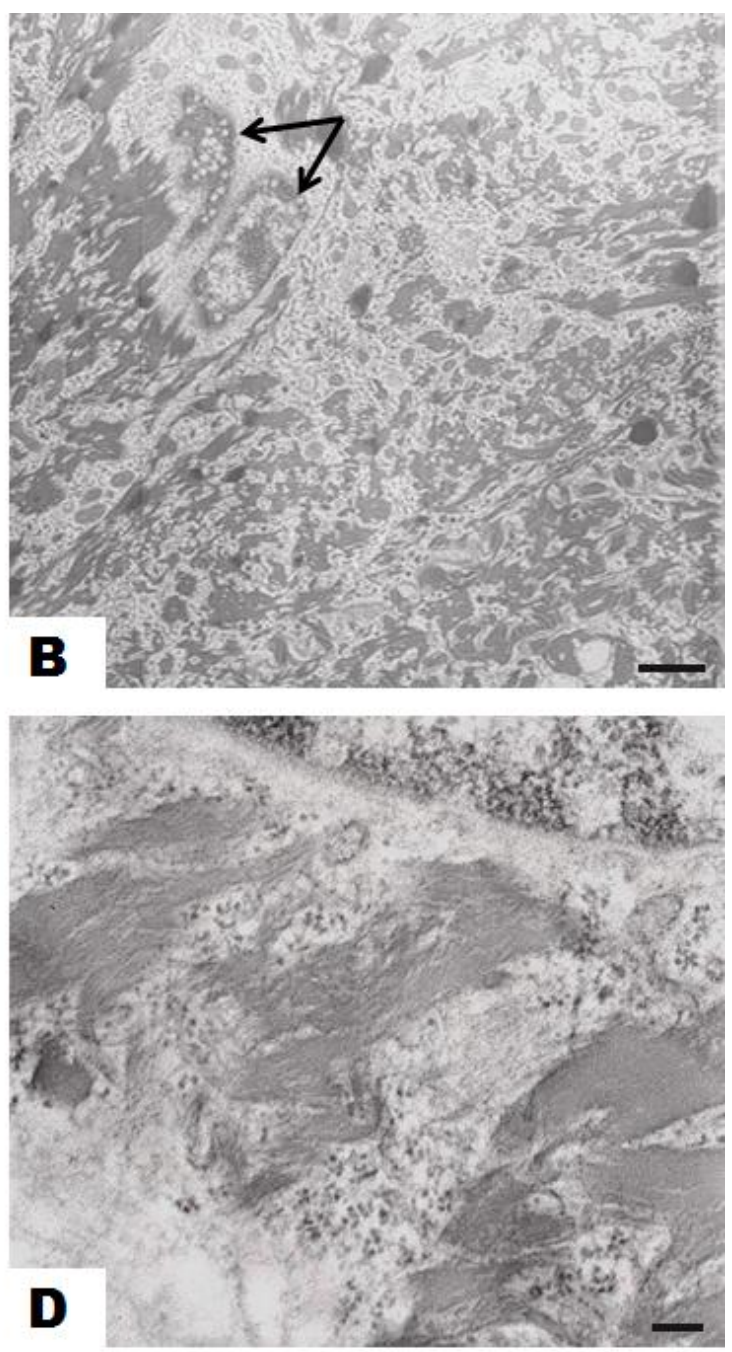

Figure 1: Bovine wart sample - Transmission electron microscopy (TEM) images of ultrathin sections: A) Cell presenting keratin fibers, nucleus with two nucleoli and well preserved nuclear membrane and nuclear pores; B) Virus-like particles (VLP) inside the cell nucleus (arrows); C) Presence of keratin fibers demonstrate high activity and massive presence of ribosomes; D) Keratin bundles net to a nucleus presenting peripheric heterochromatin. A and B: bar $=1 \mu \mathrm{m} ; \mathrm{C}$ and $\mathrm{D}: \mathrm{bar}=0.1 \mu \mathrm{m}$. 

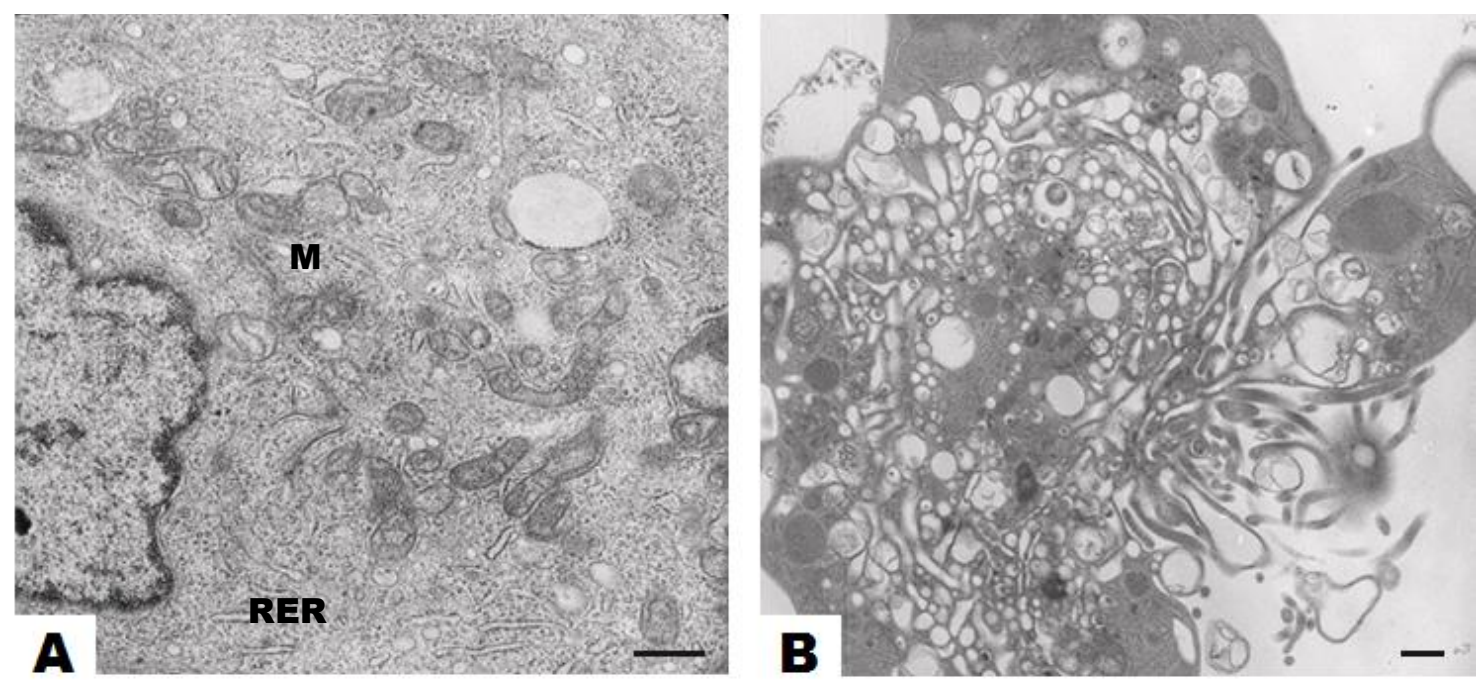

Figure 2: Cell lines - A) HeLa (HPV-18): Numerous mitochondria (M) and rough endoplasmic reticulum (RER) next to the cell nucleus indicating high cellular activity. B) SiHa (HPV-16): Cell presenting vacuoles similar to antigen-presenting cell (APC). A and B: bar $=1 \mu \mathrm{m}$

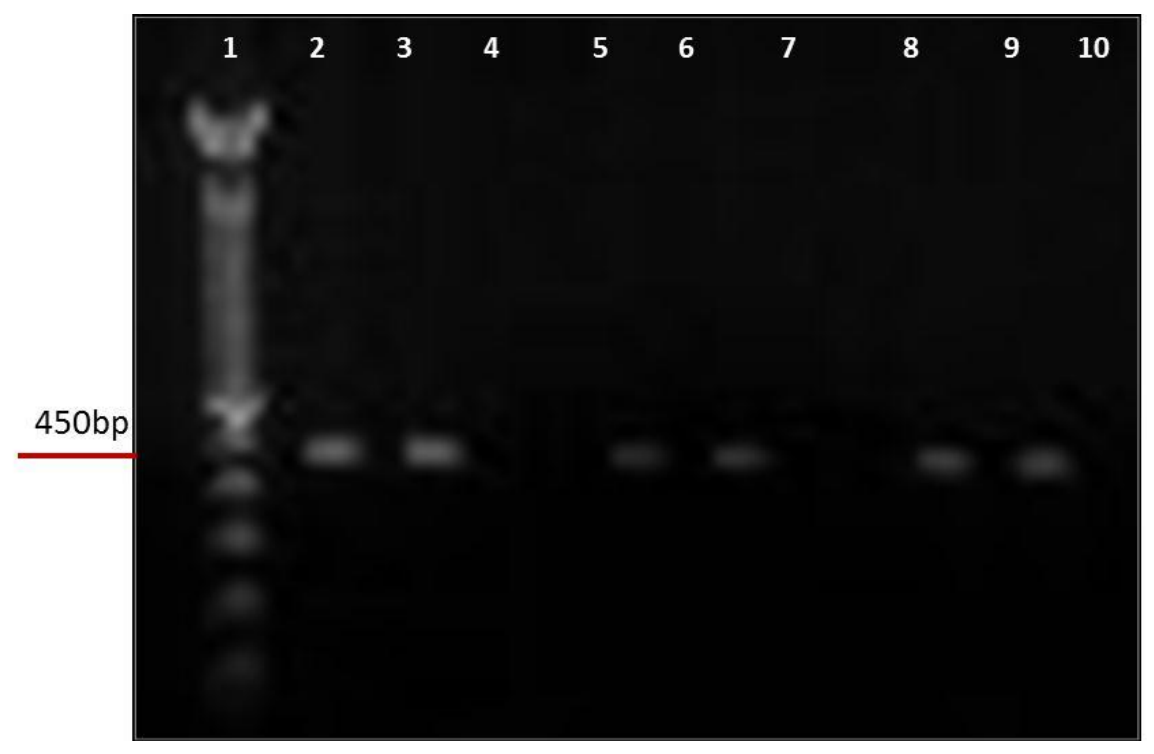

Figure 3:- Gel electrophoresis $1 \%$ of positive and control samples of $\mathrm{SiHa}$ and HeLa cell lines amplified by PCR with primers MY09/MY11 for HPV detection. 1: Ladder Marker (100bp); 2: SiHa

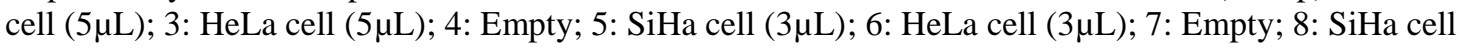
$(1 \mu \mathrm{L})$; 9: HeLa cell $(1 \mu \mathrm{L})$; 10: negative control.

\section{Discussion and Conclusion}

Stages of material processing for photonic and electron microscope analyses of the cell morphology corroborated with others authors since the inclusion of the samples in epoxy resin until obtention of semi-thin sections and ultrathin sections (De Souza, 2011).

Although of the synthetic peptide sequences were not used in our study, we detected the presence of VLP in BPV samples by transmission electron microscopy (TEM). Pease et al., (2008) demonstrated also by TEM several diagrams of VLP with different images showing VLP without packaged genomic DNA, VLP with packaged FP, 
VLP with packaged genomic DNA and VLP assembled from pentamers modified to express foreign peptide sequences on the VLP surface with packaged genomic DNA.

The data in the present report clearly demonstrated several times morphological alterations inside the BPV infected cell lines with the presence of VLP and cellular junctions like desmosomes. Immunologically, we identified cells like antigen-presenting cells (APC) in the wart lesions of BPV comparing with Merad et al. (2008) about several phenotype of APC. However, few studies have been reported about ultrastructural cell morphology in HPV cell lines and warts samples by TEM.

According Rudolph, et al. (2001), L1 capsids can trigger innate immune responses in some types of antigen presenting cells, including dendritic cells. Thus, the dendritic cell control tissue immunity is field with important implications in both basic and clinical immunology (Merad et al., 2008). So, papillomavirus vectors may be potent inducers of mucosal and systemic immunity to be useful as a molecular tool to vaccine or HPV gene therapy vehicles as described by Buck et al. (2004) and Simões \& Barth (2015).

At the National Institute of Infectious Diseases in Japan, a Japanese researcher showed typical structures of autophagosomes evidenciated by the entry of HPV pseudovirions (PsVs) in HeLa cells inoculated with 16 PsVs (Ishii, 2013). According to recent reports, the presence of large vacuoles in HeLa cells inoculated with 16PsVs as described by Ishii et al. (2013) has been reported. In our study, without inoculation of VLP in the cell lines, the same large vacuoles were observed.

The human keratinocytes in vitro of the HeLa and SiHa cell lines derived from carcinomas were immortalized by the presence of E6 and E7 genes expressed in cervix cancer (Zur Hausen, 1996). So, the ability of the cytokine to inhibit the proliferation "in vitro" of normal keratinocytes and of HPV infected keratinocytes as well as the expression of E6 and E7 oncogenes has been demonstrated by Howley et al. (2001).Ours findings indicated high cellular activity in the keratinocytes of the HPV-positive in SiHa and HeLa (HPV-18) cell lines by ultrastructural analysis, suggesting that these cells can be possible prognostic markers of cervical cancer.

\section{Acknowledgments}

The authors thank Dra. Maria Glória Bonecini and her team for technical contributions. This research was supported by Capes/Programa Brasil Sem Miséria (Brazil) and Conselho Nacional de Pesquisa e Desenvolvimento (CNPq).

\section{References}

1. Braun, T., Rudnicki, M.A., Arnold, H.H., Jaenisch, R. (1992) Targeted inactivation of the muscle regulatory gene Myf-5 results in abnormal rib development and perinatal death. Cell 71:369-382

2. Buck, C.B; Pastrana, D.V; Lowy, D.R; Schiller, J.T. Efficient intracellular assembly of papillomaviral vectors, J. Virol. 78 (2004) 751-757.

3. De Souza W (ed.). Técnicas de Microscopia Eletrônica Aplicadas às Ciências Biológicas. Terceira edição. Sociedade Brasileira de Microscopia e Microanálise, Rio de Janeiro. 2011, 423p.

4. Forslund et al. A broad range of human papillomavirus types detected with a general PCR method suitable for analysis of cutaneous tumours and normal skin. Journal of General Virology, 80 (1999), 2437-2443.

5. Huber, B., Schellenbacher, C., Shafti-Keramat, S., Jindra1, C., Christensen, N., Kirnbauer, R. Chimeric L2Based Virus-Like Particle (VLP) Vaccines Targeting Cutaneous Human Papillomaviruses (HPV). PLOS ONE, 1-27, 2017.

6. Howley, P.M., Lowy, D.R. Papillomaviruses and Their Replication. In: Knipe, D.M., Howley, P.M. (eds.) Fields Virology. 4.ed. New York: Lippincott Williams \& Wilkins Publishers, p. 2197-2229, 2001.

7. Ishii, Y (2013) Electron microscopic visualization of autophagosomes induced by infection of human papillomavirus pseudovirions. Biochemical and Biophysical Research Communications 433: 385-389.

8. Merad, M., Ginhoux, F., Collin, M. Origin, homeostasis and function of Langerhans cells and other langerin expressing dendritic cells. Nature Reviews - Immunology, v.8, 935- 947, 2008.

9. Ogawa et al. Broad-spectrum detection of papillomaviruses in bovine teat papillomas and health teat skin. Journal of General Virology, 84 (2004), 2191-2197.

10. Prati, B. Expressão de genes de vias de reparação de dano ao DNA em células infectadas por papilomavírus humano (HPV). São Paulo, 2014. 
11. Rudolf, M. P., Fausch, S. C., Da Silva. D. M., Kast, W. M.2001. Human dendritic cells are activated by chimeric human papillomavirus type-16 virus like particles and induce epitope- specific human $\mathrm{T}$ cell responses in vitro. J. Immunol. 166:5917-5924.

12. Simões et al. 2014.Virus Reviews and Research.2014, 19(2), 31.

13. Simões, R.S.Q., Barth, O. M (2015). Papillomavirus: Viral vectors in the gene therapy and new therapeutic targets. International Journal of Biomedical Research 2015; 6(10): 763-768.

14. Tyring S.K (2000). Human papillomavirus infections: epidemiology, pathogenesis, and host immune response. J Am Acad Dermatol, 43, S18-26.

15. Yaguiu et al. Papillomatosis in cattle: in situ detection of bovine papillomavirus DNA sequences in reproductive tissues. Brazilian Journal of Morphological Science, 23 (2006), 129-136.

16. Zur Haussen, H. Papillomavirus infections a major course of human cancers. Biochim Biophys Acta, 1996, 1288 (12) : 55-78. 